Note

\section{Preparation of Chalara paradoxa Glucoamylase Modified by Fluorescein-isothiocyanate and Binding to Raw Starch ${ }^{\dagger}$}

\author{
Mitsuru Monma and Keiji KaInuma \\ National Food Research Institute, Ministry of \\ Agriculture Forestry and Fisheries, \\ 2-1-2 Kannondai, Tsukuba, Ibaraki 305, Japan
}

Received December 16, 1987

Recently Kainuma et $a .^{1 \sim 4)}$ reported a kind of raw starch digesting amylase from Chalara paradoxa. There have been several reports on raw starch digesting amylase binding to raw starch by assaying the remaining activity or protein in the supernatant ${ }^{5,6)}$ In this paper, we report a new method for studying glucoamylase binding to raw starch using fluorescein-isothiocyanate modified Chalara paradoxa glucoamylase.

The glucoamylase from Chalara paradoxa was prepared as previously reported ${ }^{3,4)}$ with a slight modification. Fluorescein-isothiocyanate (FITC) was coupled with the glucoamylase by the method of Hiramatsu et al. ${ }^{7}$ Twenty milligrams of the glucoamylase preparation was dissolved in $1.6 \mathrm{ml}$ of $0.1 \mathrm{M}$ carbonate buffer $(\mathrm{pH} 8.3)$ and mixed with $2.5 \mathrm{mg}$ of FITC $\left(\varepsilon_{494}=7.54 \times 10^{3}\right.$, Merck $)$ in the same buffer $(0.4 \mathrm{ml})$, then incubated $30^{\circ} \mathrm{C}$ for $3 \mathrm{hr}$. Unreacted dye was then removed by passing through a Toyopearl $40 \mathrm{~S}$ column and by an $\alpha$-CD Sepharose $6 \mathrm{~B}$ column. ${ }^{4)}$ This solution that contained both free glucoamylase and FITClabelled glucoamylase was used in this study without further purification. Contamination by free dye in the sample was checked by thin layer chromatography using a silica gel $60 \mathrm{~F}_{254}$ sheet (Merck) irrigated with 1-butanol-1propanol-water $(3: 5: 4)$; then no free dye was detected. The ratio of dye to glucoamylase was estimated to be about 0.5 by measuring the dye concentration by spectrophotometry, and the glucoamylase $\left(M_{w}, 78,000\right)$ con-
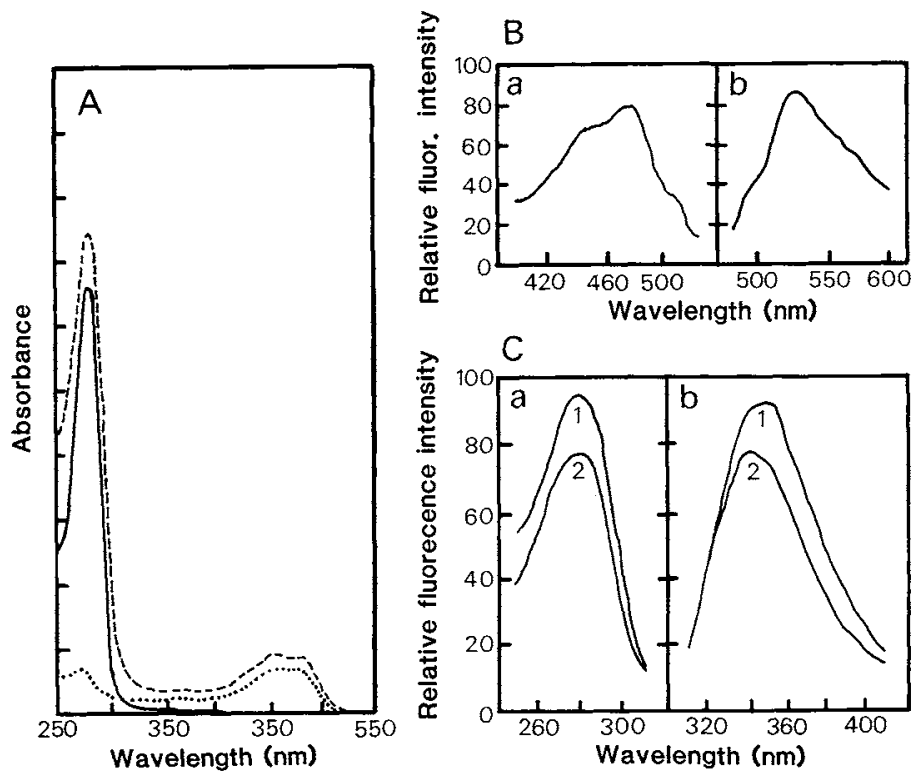

FIG. 1. Absorption, Excitation, and Fluorescence Spectra of FITC Modified Chalara paradoxa Glucoamylase.

A: absorption spectra. —_, native glucoamylase; ------, free FITC, ----, FITC modified glucoamylase. The absorbance scale is arbitrary. B: excitation and fluorescence spectra of FITC modified glucoamylase. a, excitation spectrum emitted at $520 \mathrm{~nm}$. b, fluorescence spectrum excited at $490 \mathrm{~nm}$. C: excitation and fluorescence spectra of native and FITC modified glucoamylase. a, excitation spectra emitted at $340 \mathrm{~nm}$. b, fluorescence spectra excited at $280 \mathrm{~nm}$. 1, native glucoamylase; 2, FITC modified glucoamylase.

$\dagger$ Studies on the Novel Raw Starch-digesting Amylase Obtained from Chalara paradoxa. Part XIII.

This work was supported in part by a Grant-in-Aid for the Biomass Conversion Project (BCP-87-V-1-2), Ministry of Agriculture, Foresty, and Fisheries of Japan.

Abbreviations: FITC, fluorescein-isothiocyanate; $\alpha-C D$, alpha-cyclodextrin. 

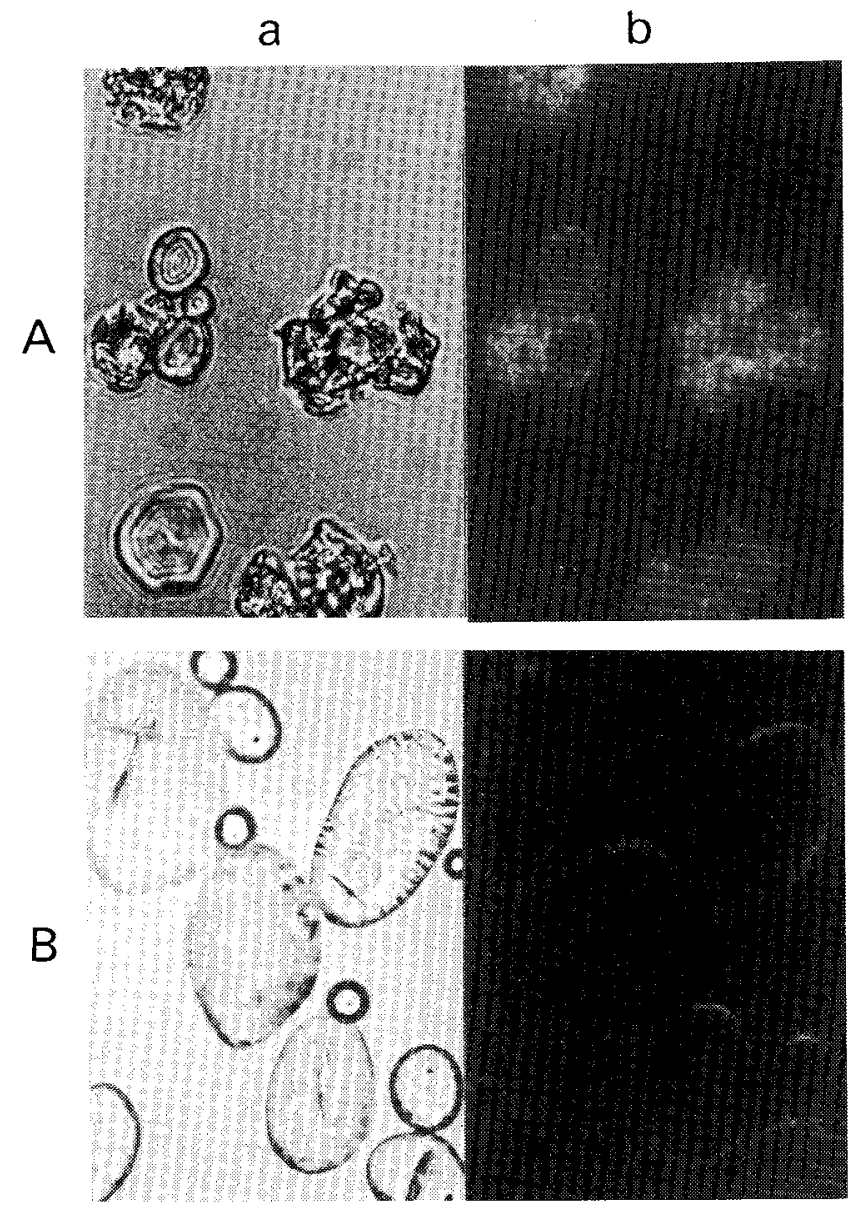

Fig. 2. Micrographs of Corn (A) and Potato (B) Starch Mixed with FITC Modified Glucoamylase.

Each $2 \%$ starch digested by native glucoamylase was mixed with $200 \mu$ l of modified glucoamylase (about $36 \mu \mathrm{g}$ ). a, normal micrograph. b, microgarph under fluorescence microscope.

centration by Lowry's method ${ }^{8}{ }^{8}$ The prepared glucoamylase had $83.4 \%(47.2 \mathrm{U} / \mathrm{mg})$ of the specific activity of the original glucoamylase, and the modified glucoamylase bound to raw corn starch as well as the native enzyme; almost $80 \%$ of the activities were bound to starch granules. The binding of glucoamylase to raw starch was estimated by measuring the activity in the supernatant after incubating 2 units of glucoamylase with $100 \mathrm{mg}$ of raw starch in $1 \mathrm{ml}$ of acetate buffer $(\mathrm{pH} 5.0)$ at $40^{\circ} \mathrm{C}$ for $20 \mathrm{~min}$. Figure 1 shows the general characteristics of absorbance and fluorescence spectra of the native glucoamylase, free FITC, and FITC-labelled glucoamylase. The labelled glucoamylase had an emission maximum at $520 \mathrm{~nm}$ (excited at $490 \mathrm{~nm}$ ), and excitation maxima at the wavelengths $465 \mathrm{~nm}$ and $490 \mathrm{~nm}$ (emitted at $520 \mathrm{~nm}$ ).

The preliminary study with native raw starches could not have revealed any difference in the binding of FITClabelled glucoamylase because of inactivation of the glu- coamylase or quenching of FITC fluorescence during incubation. Raw starches used in this study had been formerly digested by glucoamylase for 3 days (potato and sago) or $24 \mathrm{hr}$ (corn and rice) at $40^{\circ} \mathrm{C}$, in $25 \mathrm{~mm}$ acetate buffer ( $\mathrm{pH} 5.0$ ). The digestion percentages were $47 \%$ (potato starch), 62\% (sago starch), 72\% (corn starch), and $59 \%$ (rice starch). Figure 2 shows ordinary micrographs and fluorescence micrographs of potato starch and corn starch, $(2 \%$ in $200 \mu \mathrm{l})$ mixed with Chalara glucoamylase (about 5 units). These micrographs were taken with a Nikon XF-II with EFD fluorescence apparatus. As shown in Fig. 2 several granules of corn starch gave fluorescence (green color) in the whole granule, but potato starch gave fluorescence almost only on the surface. Sago starch and rice starch also had fluorescence pattern like potato starch (data not shown). As there was almost no fluorescence of the starch granules when modified glucoamylase was mixed with starch in the presence of sodium dodecyl 

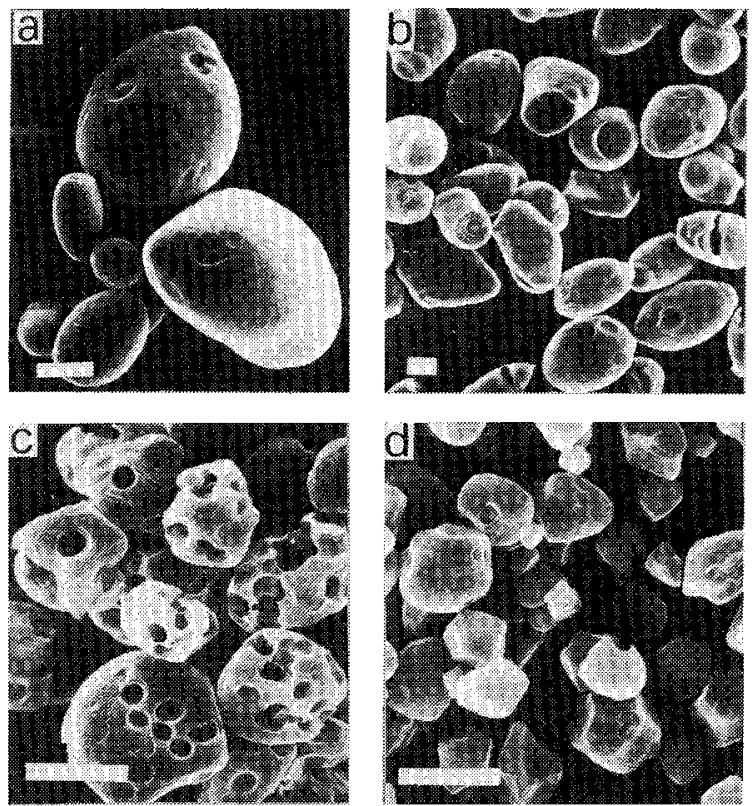

FIG. 3. Scanning Electron Micrograph of Starches (The bar represents $10 \mu \mathrm{m}$ ).

Starches were digested by native glucoamylase to the digestion percentage of potato, sago, corn, and rice, 47 , 62,72 and $56 \%$, respectively. a, potato, b, sago. c, corn. d, rice.

sulfate (SDS), we considered the fluorescence observed on starch was due to the specific binding of modified glucoamylase to starch. The scanning electron micrographs in Fig. 3 showed digestion patterns of these starches by native Chalara paradoxa glucoamylase. Among these starches only corn starch was digested to the center of the granule to a porous structure by digging deep cavities, but all of the other starches (potato, sago, and rice) studied here were digested probably only at the surface of the granules by digging cavities. Because of this porous structure of corn starch, under the fluorescence microscope only corn starch had fluorescence in the whole granule by binding modified glucoamylase within the holes.

In conclusion, the glucoamylase of Chalara paradoxa modified with FITC was bound to starches and gave fluorescence under the microscope. The pattern of fluorescence in starch granules was related to the digestion pattern by the glucoamylase.

\section{REFERENCES}

1) K. Kainuma, H. Ishigami and S. Kobayashi, J. Jpn. Soc. Starch Sci., 32, 136 (1985).

2) H. Ishigami, H. Hashimoto and K. Kainuma, J. Jpn. Soc. Starch Sci., 32, 189 (1985).

3) H. Ishigami, H. Hashimoto and K. Kainuma, J. Jpn. Soc. Starch Sci, 32, 197 (1985).

4) M. Monma, K. Mikuni, H. Ishigami and K. Kainuma, Carbohydr. Res., 159, 255 (1987)

5) S. Hayashida, Agric. Biol. Chem., 39, 2093 (1975).

6) B. Chandra and S. Ueda, J. Ferment. Technol., 62, 67 (1983).

7) M. Hiramatsu, N. Okabe and K. Tomita, $J$. Biochem., 73, 971 (1973).

8) O. H. Lowry, N. J. Rosebrough, A. L. Farr and R. J. Randall, J. Biol. Chem., 193, 265 (1951). 